\title{
Effects of Water Cleaning on Different Deposit Types: An Experimental Study Combined with Mathematical Investigations
}

\author{
Franziska Graube-Kühne ${ }^{1,3}$ DD $\cdot$ Nina Heißen ${ }^{2} \cdot$ Sebastian Grahl $^{1} \cdot$ Michael Beckmann $^{1} \cdot$ Bhaumik Patel $^{2}$
}

Received: 20 August 2019 / Accepted: 13 February 2020 / Published online: 25 February 2020

(c) The Author(s) 2020

\begin{abstract}
The deposits in waste incinerators are commonly removed with cleaning systems. Hitherto, the power plants lack the possibility to adjust the cleaning optimally to the specific situation. As a result, the cleaning sometimes has no effect and the deposits remain on the walls, while another time, the cleaning is applied too frequently and may result in damage of the water walls. The current paper evaluates investigations of the cleaning effects of water cleaning systems and their dependency on deposit properties. Real deposits are classified regarding their properties with focus on water cleaning systems. A mathematical model is established which calculates the dominating cleaning effect for known deposits and firing parameters. Firstly, a parameter study analyzes the influence of the deposit's porosity, material properties, structure and layer thickness on the cleaning results. Afterwards, the model is applied to a real incinerator and three actual cleaning procedures are evaluated concerning their suitability to the existing impurification. The results demonstrate the principal assessment ability of the cleaning cycle and reveal weak points that have to be considered in cleaning setups.
\end{abstract}

\section{Graphic Abstract}

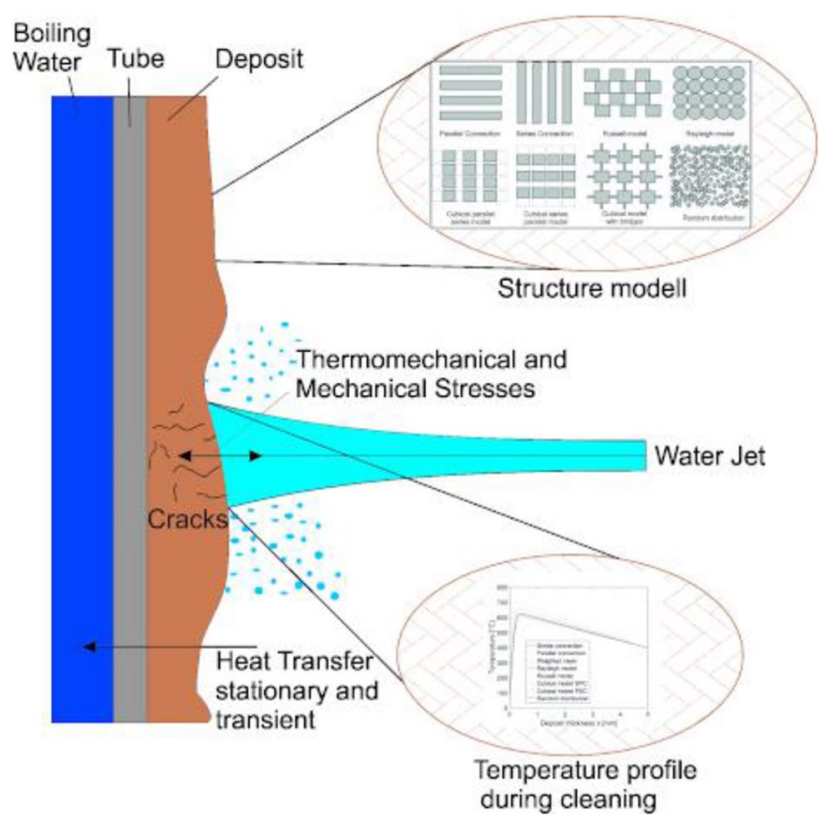

Keywords Water cleaning · Waste combustion · Cleaning adjustment $\cdot$ Shower cleaning $\cdot$ Water jet cannon · Thermomechanical stress

Extended author information available on the last page of the article 


\section{Statement of novelty}

The current work helps to better understand the cleaning process and meanwhile to describe the deposit. Thereby, the cleaning process is adjusted appropriately to the deposit.

\section{Introduction}

The combustion of waste releases a variety of components, which cause deposits on the water walls. These components might be silicates, sulphur, aluminum, nitrides and in lower quantities chlorine, heavy metals and others [1-3]. The deposits, consistently, limit the heat output, and, additionally, react corrosively. This may lead to a damage of the water walls [4]. Both heat output and corrosion potential strongly depend on the deposit composition. Namely, their physical properties solidity, thermal conductivity, porosity and others as well as the chemical properties are component-dependent. To protect the water walls and to maximize the heat output, many cleaning systems are established to remove the deposits. Some of them operate online, while others clean the boiler during shutdowns of the power plant. Because of their ability to clean the combustion chamber during operation, the online cleaning systems are of great importance in order to maintain long operational time. These systems can be classified into two groups: cleaning systems that work without an additional medium or cleaning systems that use an extra medium, e.g. water or bullet rain [5]. A detailed description of established online cleaning methods can be found in [6]. The use of water for deposit removal is a widely spread method. Advantages are a good availability and comparably low costs in contrast to e.g. soot blowers [7]. Additionally, the water cleaning systems are able to operate online and they have a number of adjustable parameters. Due to the prevalence of the water cleaning systems, this paper focuses on those, only. Regardless of the specific cleaning system, the physical background of water cleaning setups can only be based on one of three physical effects, to wit the thermomechanical stress, the momentum of the water including erosion effects or the evaporation pressure [8]. Additionally, non- physical effects may influence the cleaning, to wit dissolving of salt and chemical reactions. Scope of the present article are the physical effects mentioned above.

There are three common types of water cleaning systems, namely shower cleaning systems, water blowers/ water lance blowers and water jet cannons [9] that will be presented in the following. Conventional soot blowers mainly use steam or air and, thus, are not considered in the mathematical calculations further down and, hence, are not described in detail. Principally, the results presented in the current paper can be transferred to soot blowers as well. A further development are water lance blowers with rotating nozzles, which clean the superheater gaps. They are not listed separately. These sootblowers clean more target-oriented and are commonly used as alternative to soot blowers in waste and biomass incineration. The shower cleaning system has a spray nozzle, which moves downwards from the top of the incinerator paths. The cleaning is achieved through thermomechanical stress, the dissolving of salt and the penetration of water. A cleaning by the momentum is possible if the momentum exceeds the adhesive force [5], but is less important compared to other cleaning systems due to the low water pressure. Shower cleaning systems are typically installed in waste incinerators. Adjustable parameters of these systems are the amount of water, the water pressure, the retention time of the nozzle and the nozzle shape. Water jet cannons operate from the side of the boiler opposite the deposit or from the sidewalls angular to the deposit. Water blowers face backwards, so that they clean the wall around their entry position. Both work similar. Principle possible cleaning effects are the momentum, the thermomechanical stress and the penetration of water. The systems are suitable for larger boilers. The adjustable parameters of water jet cannons and water blowers are the cleaning pattern, the amount of water, the movement speed of the nozzle and the residence time [6]. These cleaning systems follow cleaning patterns, which are adopted to the deposit locations inside the boiler.

The efficiency of the cleaning result highly depends on the adjustment of the cleaning to the deposit structure and deposit properties. Properties and structure are closely related. Many scientists aimed on classifying deposits. In general, deposits are distinguished in slagging and fouling, though the comprehension of slagging and fouling is not completely similar everywhere. Gumz [10] differs between slagging and fouling as the following: Molten and partly molten fly ash form slagging. The melting may also include non-molten parts. However, fouling encompasses detached fly ash that may form layered or non- layered deposits. Hansen [11] investigated such a fouling in straw- fired boilers. He detected two types of deposits. The first one could be collected with a cooled probe that remained under the roof of the first and second path. The deposit consisted of two layers. The inner layer was a corrosive potassium chloride layer. The outer layer showed sintered parts. A second type originated from the super heaters and consisted of six layers, having iron oxide at the inside and potassium chloride outside. The central layers where comparably porous. Following these scientists, more classifications are conceivable. 
Zelkowski et al. defined fouling as deposit in the convective part and slagging as deposit in the radiative part of steam generators [12]. Besides the location of appearance, several other effects affect the deposit structure. For both biomass and waste incineration the fuel composition is of great importance [1]. That is, because the constituents do not only react chemically different on the walls, but may also decrease the ash melting behavior and, thereby, change the deposition propensity. Besides, the process parameters influence the deposits, such as the mass flow of the process air and the flue gas. Especially the temperature range along the flue gas duct is of high importance [12]. Despite the influences of the above mentioned parameters, the deposit passes an alteration process also called deposit aging. The aging process starts with a thin highly insulating layer, which grows while collecting gritty particles. While the deposit grows further, it starts to densify until it starts to sinter. Finally, slag flow may occur. Operators try to detect and remove deposits before they reach the slag flow [13].

The current state of the art allows a localization of deposits. Several measurement systems use different physical effects to detect deposits. A possible measuring system is an infrared camera [14], which delivers thermal images of the water walls. Pyrometers have a similar functionality [15]. They are more affordable in price, but the result is more limited to local spots whereas infrared systems survey a wide area. Besides these systems another popular method is the installation of thermocouples or heat flux sensors at the backside of the water walls or inside the tubes respectively. The sensors are used to measure either the surface temperature or the heat flux. They distinguish the effect of cleaning as they measure continuously. Thus, the cleaning parameters can be adjusted for the next cleaning. To optimize the cleaning even more, knowledge of the deposit properties is necessary. Thus, Grahl [13] developed a deposit sensor that evaluates the time shift and the damping of transient temperature changes. The sensor is a combination of a pyrometer or infrared camera and a heat flux sensor or a thermocouple. Basis is the calculation of the transient temperature profile within the deposit. This combination enables the estimation of the deposit properties thermal conductivity, density, thermal heat capacity, deposit strength and deposit thickness. The sensor delivers deposit data. Besides, deposits may be detected with a laser distance sensor. Such a system is presented in [16]. A laser distance sensor is combined with a motorized mirror allowing the scan of the opposite boiler wall. The measurement of the deposit distance is inversely proportional to the deposit thickness. At the current state, the laser distance sensor could only be installed at wasteand biomass- fired power plants, through the large scale and the high dust rate of coal- fired boilers. The laser distance sensor measures the deposit thickness $\pm 1 \mathrm{~mm}$ accurately. Details about the setup can be found in [16]. Especially the combination of deposit sensor and laser distance sensor is promising, because the deposit sensor as standalone system only estimates the deposit properties. The known deposit thickness makes a measurement of the specific properties possible. To transfer the data obtained with the deposit sensor and the laser distance sensor to an adjusted cleaning setup, the mathematical description of the cleaning process has to be specified as well. The following chapter presents experimental methods to analyze the cleaning process. Afterwards, a mathematical model is described, which calculates the heat transfer inside the deposits during the cleaning procedure.

\section{Experimental Methods}

\section{The Droplet Apparatus}

Part of the experiments is a setup to investigate deposits online and to examine cleaning efficiency. The focus lays on the cleaning with water and the effect of droplets on hot deposits. The apparatus involves a cooled probe which dwells in the incinerator to collect deposits (Fig. 1a). The apparatus is designed in such a way, that it can be used at every possible boiler orifice regardless of the incinerator type or the location inside the incinerator (e.g. super heater and radiative section are both possible). The apparatus is flanged to the boiler. Thus, only the adapter flange needs to be adopted to each boiler. After a certain retention time, the probe is pulled back into a heated chamber (Fig. 1b). There the deposit may be analyzed regarding cleaning behavior and material properties. As presented in [17], the apparatus has several features, namely a droplet applicator, a hardness measurement system, a pyrometer measuring at two wave lengths and an access orifice for a high speed camera. The setup of the apparatus is depicted in Fig. 1.

The apparatus shall be extended with a Raman spectrometer, a water spray nozzle and an air pulse. The droplet applicator, the water spray nozzle, the air pulse and the hardness measurement system all serve to separate the cleaning effects, especially the thermomechanical stress and the momentum. The other measurement setups are useful to detect and classify different deposit types. The apparatus was installed in several waste incinerators and one coal combustor to collect as many different deposit types as possible. At the current state of research, the deposit types all originate from the radiation section. The investigations will be expanded to the superheaters in the future. Also, the application in biomass-fired boilers is possible. Table 1 shows the hitherto detected deposit types. More groups are conceivable. All these deposits were applied with twenty droplets to detect thermomechanical cracking and the dissolution of salt.Figure 2 

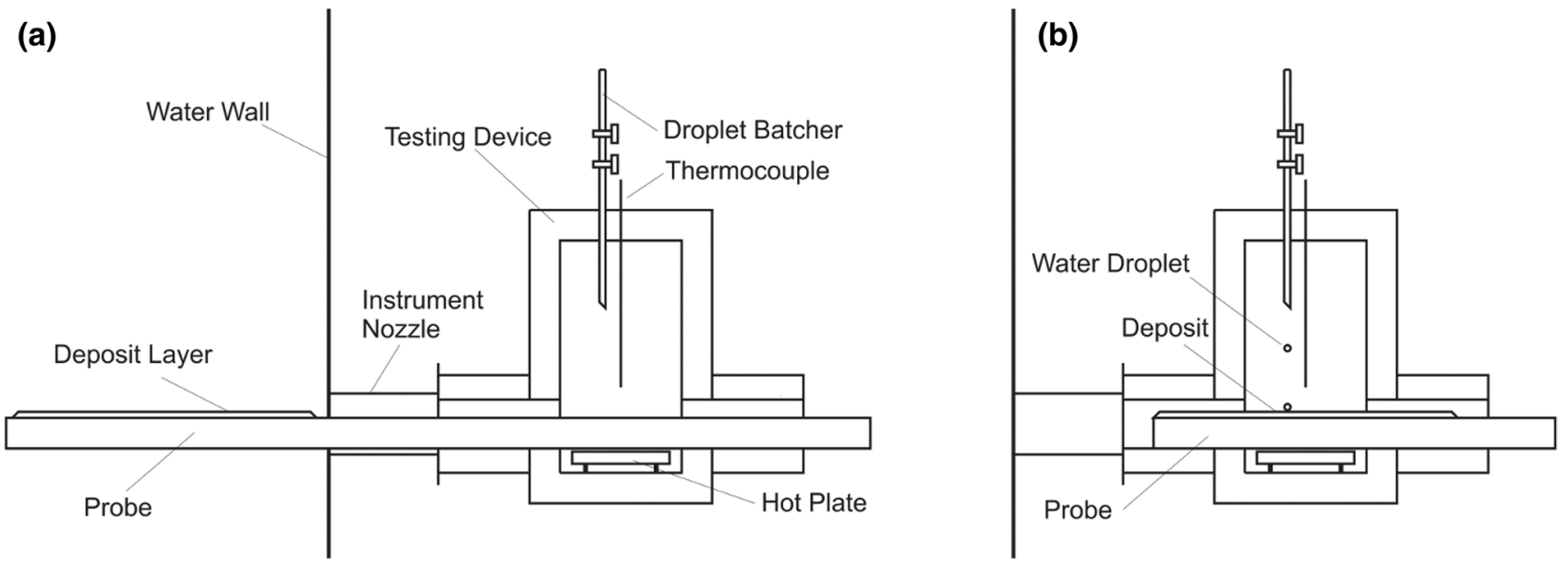

Fig. 1 Droplet apparatus: a Probe collects deposit; b Deposits are analyzed inside the heated chamber [5]

Table 1 Classification of deposits ([5] and actual extension [17])

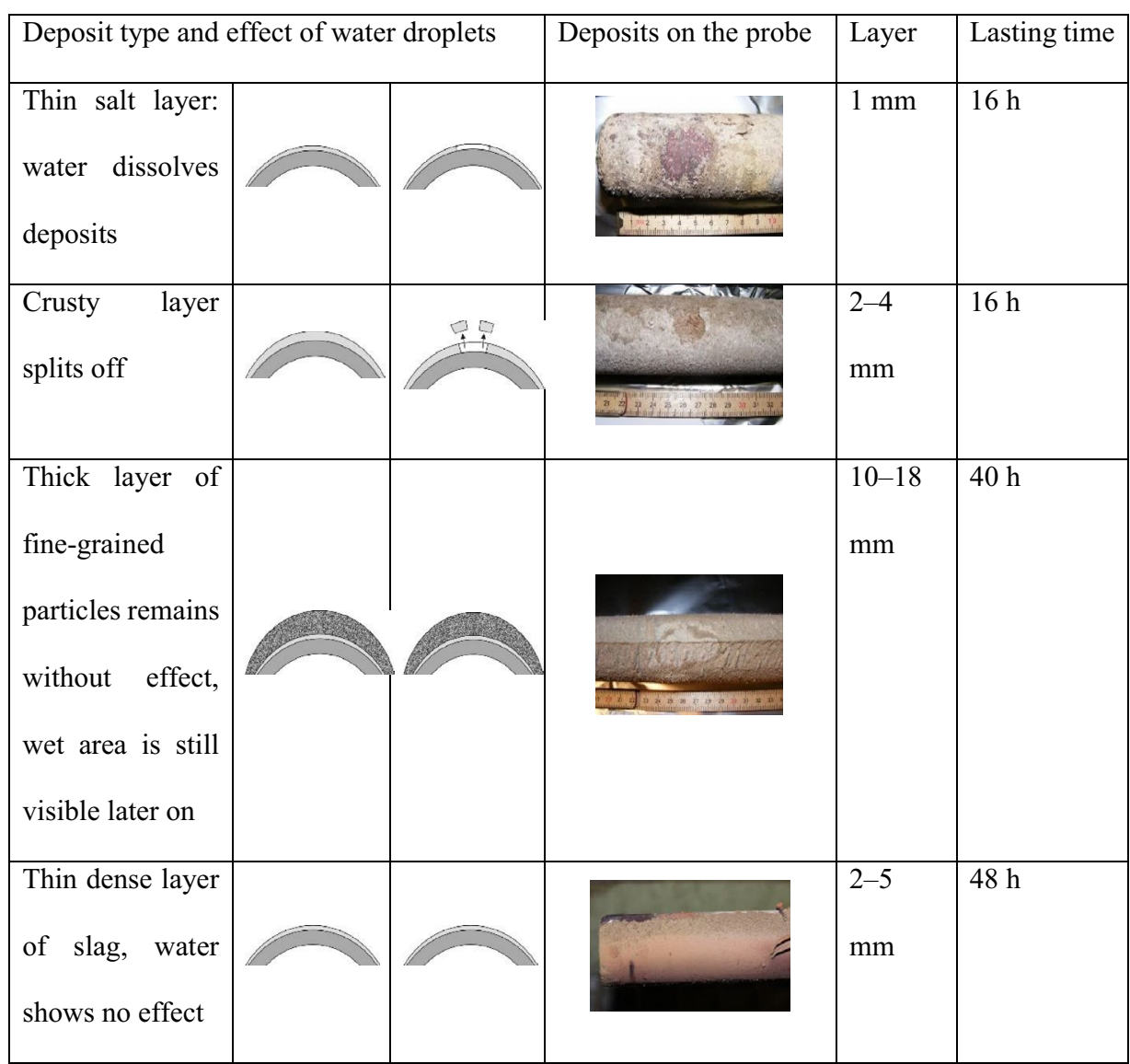

shows two deposits that were impacted with twenty droplets of water. Figure 2a shows that cold water leads to high thermomechanical stress resulting in a rupture of the deposit. Figure 2 b shows washout of salty parts where the droplets hit the tube.
As expected, the different cleaning effects match different deposit groups. The cleaning effect through the droplets is presented in the Table 1 as well.

The large differences in the droplet effects show the importance of an adjusted cleaning. To improve the 
Fig. 2 a Cracking through thermomechanical stress. b Dissolution of salt [17]
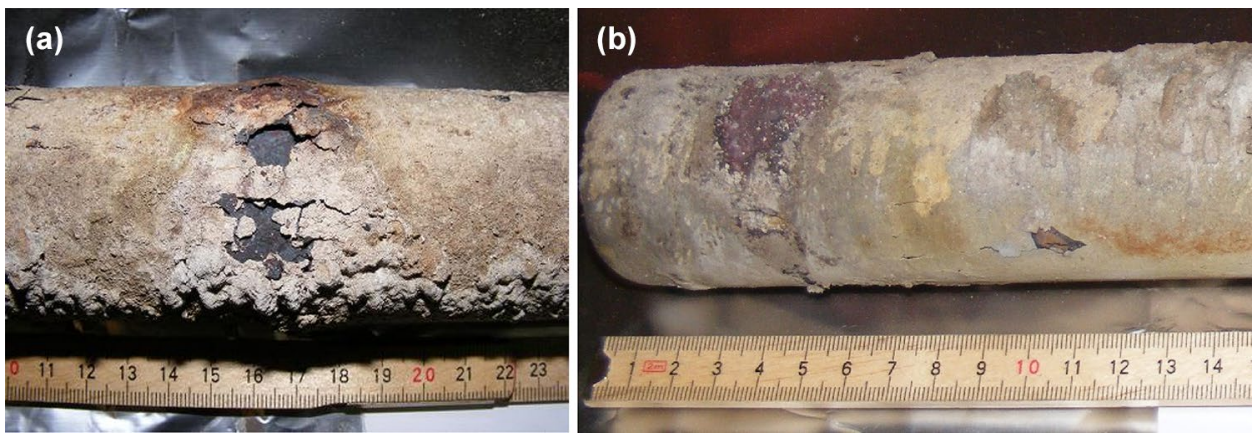

significance of the results, several approaches shall be made. Firstly, the impact point of the droplets is investigated in detail. Secondly, the property analysis is extended to further deposit samples to increase the data base.

\section{Investigation with Droplets}

The aforementioned apparatus is not only useful to classify deposits. It also allows the analysis of the water during contact with the deposit. Hitherto, the analysis of wetting depending on the surface properties and the surface temperature is possible. For the execution of these investigations, a high-speed camera is installed at the optical inspection port. The camera records the droplet's descent and impact on the tube. The experiment can be realized with hot and cold deposits. The temperature of the deposit must be adjusted prior to the experiment. Aim of the experiment is the improved wetting of deposits. The wetting affects the penetration of water into the deposit as well as the cooling of the deposit's surface which leads to thermomechanical shock. For comparison, Table 2 summarizes the wetting effect of a droplet on a hot plain tube, on a hot deposit and on a cold plain tube. Seven pictures are singled out of the high- speed video, videlicet the appearance of the droplet, the impact moment, the ripping of the droplet, the spreading of the water at two time points and the disappearing of the water. Table 2 presents pictures of droplets on the probe.

Each sequence shows the dropping of a single water drop onto a surface. The first sequences shows the hot plain tube, the second the hot deposit. Both have an outer surface temperature of $350{ }^{\circ} \mathrm{C}$, the third one is a blank metal tube at ambient temperature. The deposits visible in the second sequence were collected at a testing field burning coal dust. Subject of the different surface structures is the investigation of the penetration behavior. A droplet is not able to penetrate into the steel but into the porous deposit. Preceding experiments analyzed the wetting and penetration of deposits under ambient conditions. All deposits soaked the water

Table 2 Impact of droplets on different hot and cold surfaces

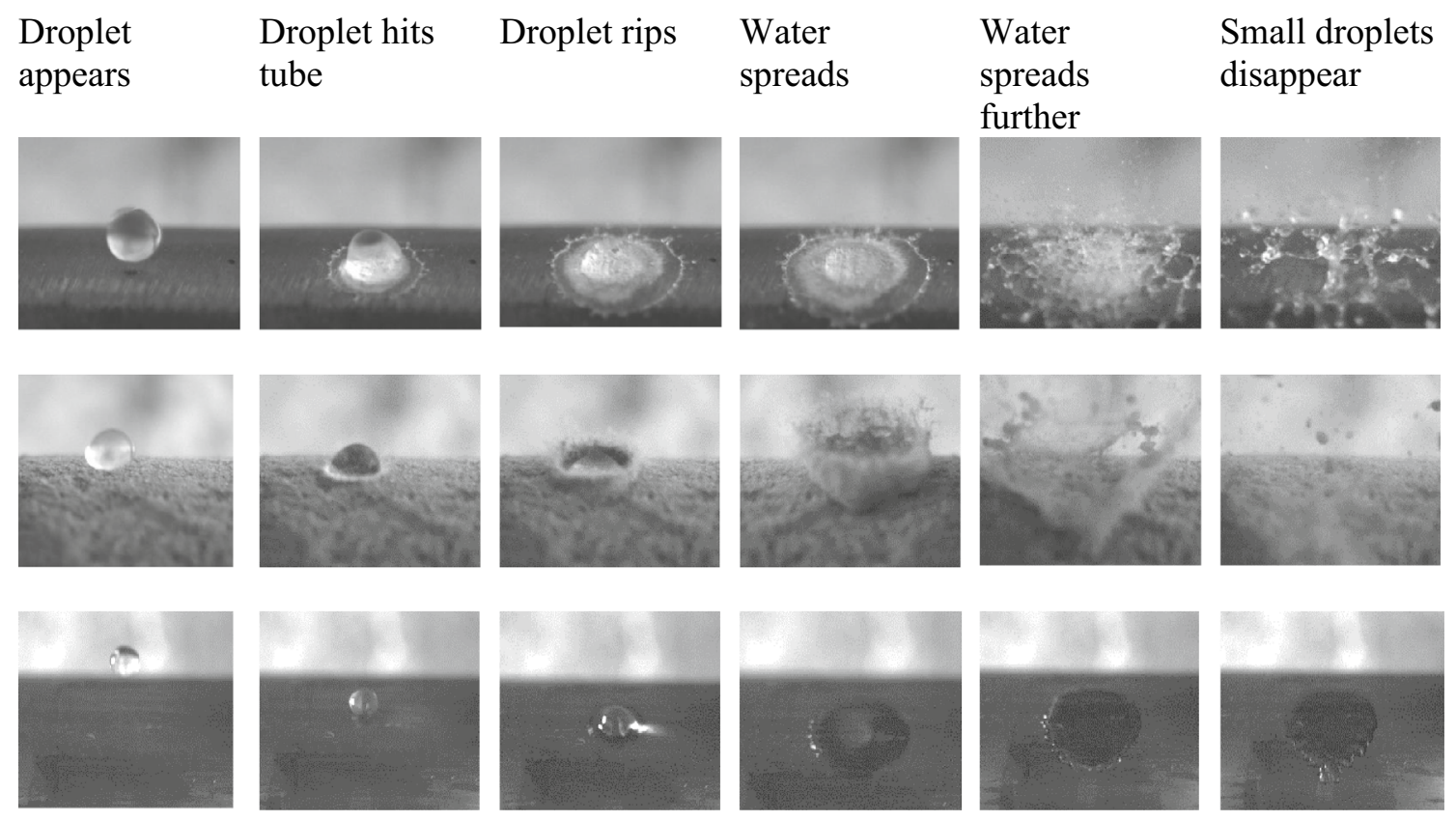


droplet completely, making the determination of a wetting angle impossible. Based on this, the cold blank metal tube was chosen for comparison instead of a deposit.

The droplets impacting the hot surfaces show different behaviors: Both droplets are ripped into small droplets, but the droplet impacting the plain tube spreads lateral, while the droplet hitting the deposits moves back upwards. Even though both droplets show different behaviors during the impact, the droplets touching the heated surfaces illustrate the Leidenfrost effect respectively [18, 19]: The impact of the falling droplet suffices to destroy the cohesion. The high temperature results in a fast evaporation of the outer droplet layer establishing a steam film between the rest of the droplets and the hot surface. As a result, the small droplets move above the surface without touching the surface material, as the steam film is a cushion in between. Besides, by wetting the cleaning effect may also be investigated by using the high-speed camera. In the current case, no cleaning effect is visible due to the large droplet, reason may be the reduced contact due to the steam film. Nonetheless, further observation of the impact shows that the small droplets with high velocity after the burst accomplish a material removal, presumably through the high momentum. The cold tube shows a droplet that is dripping off the surface. A wetting is possible through the absence of the Leidenfrost effect.

It is to be expected, that several deposit groups show similar effects. Thus, only surface effects will be considered in the mathematical model. It means in effect, penetration into pores and thermomechanical stresses at local spots are not part of the model. Hence, all effects based on that are neglected, e.g. pore evaporation, and have to be analyzed in another scope. Additionally, the result points out, that the temperature level of the cleaning water affects the cleaning efficiency.

Not only the effect of droplets shall be investigated. Other coincidences are of interest, too. To extend the results from the deposit characterization, the properties of deposits shall be associated with each other and with the deposit's components. On that basis follows a deposit analysis considering different properties. Later on, the mathematical model is used for a parameter study to evaluate properties mathematically. Part of the parameter study are the deposit's porosity, layer thickness, thermal diffusivity and deposit structure and their influence on the temperature distribution inside the deposit and the occurring stress level. The parameter study is followed by a contrasting comparison of the temperature level and occurring stresses.

\section{Analysis of Deposit Samples}

The collection of deposits with the droplet apparatus is very time consuming and limited to accessible locations. Therefore, the investigation is expanded to deposits collected during shut downs in power plants. The first group of examined deposits originates from plants fired with Rhenish lignite. Nonetheless, the results are equally valid for wastefired, biomass-fired and coal-fired power plants, because aim is the analysis of property coherences.

The multitude of possible samples makes a complete study impossible. Hence, only spot samples are possible. Three locations inside a coal-fired boiler were selected, at which a detailed analysis shall be performed with several samples. Three locations inside a coal-fired boiler were selected, at which a detailed analysis shall be performed with several samples. They all originate from the super heater section at different temperature levels. Later on, the analysis also shall incorporate samples from waste-fired boilers and biomass-fired boilers. The analyzation of the deposits is still afoot. The preliminary results are presented in the following. Objectives of the analysis were those printed in Table 3.

The X-Ray analyzation was realized for test purposes on two probes only using computer tomography. The X-Ray analyzation allows the assessment of the inner deposit structure. The density of salty layers differs distinctly from the iron oxide layers or silicates. Thereby, the inner buildup e.g. in layers or as homogeneous deposit with material needles is visualisable. The results obtained with the tomography were very promising. Thus, the data acquisition will be expanded to all deposit probes. Knowledge over the inner structure is important for the choice of the heat transfer model. The heat transfer models will be presented further down. The porosity and density are both evaluated using the inert gas helium. While the porosity was measured leaving the sample as is, the density was determined by graining the deposit. The analysis was realized using a gas pycnometer. The porosity measurement also encompasses the determination of the pore size distribution. Even more important than the measurement of the porosity is the measurement of the open porosity. Therefore, all samples were examined at least at five positions using a laser microscope. By applying the microscope, both the pore density and the pore size are measureable. In general, the results fit very well to the helium porosity measurements.

The deposit state highly depends on its deformation point. Liquid and softened deposits stick to the water walls, whereas solid ash needs a sticky surface or other bonding

Table 3 Summary of the laboratory analysis

\begin{tabular}{ll}
\hline The elemental composition (XRF) & $\begin{array}{l}\text { The surface structure } \\
\text { The helium density }\end{array}$ \\
$\begin{array}{l}\text { Therosity including the } \\
\text { pore size distribution } \\
\text { Melting characteristic }\end{array}$ \\
Compressive strength & Thermal conductivity \\
Microsections & Mineal composition (XRD)
\end{tabular}


mechanisms to form deposits on the walls. Hence, the deformation temperature of the deposits is determined using an ash melting microscope. The ash melting microscope can be used to obtain the deformation point, the melting point, sintering behavior and others. Here, the deformation point is of great importance, because it is the set point value for the stickiness of the deposit. The component analysis is made first elemental, followed by a mineralogical examination. Thereby, vital influence of specific elements can be determined as well as property changing mineral compositions. The elemental analysis is realized using an XRF spectrometer, the follow up mineralogical analysis is conducted using an XRD. The results of the realized investigations are summarized in Table 4. Type two and three originate from the same position, but show some differences and, thus, are separately listed in the table. The XRF results are not presented in full, but the vital elements are included.

The analysis of the compressive strength, the thermal conductivity and the micro section will follow later on. As expected, the porosity differs strongly depending on the deposit type. Mainly, the pore sizes range between 10 and $100 \mu \mathrm{m}$. Thus, further analysis of the water penetration should focus on these orders of magnitude. Additionally, the porosity remains one of the main parameters that shall be considered in the following model to determine its influence on the cleaning procedure, because the porosity varies between 18 and $56 \%$. The density of the raw material is similar for all deposits independent of the porosity. The pore size is likewise not porosity- dependent. The deposits with the largest and the smallest porosity have equal pore size distributions. For the actual deposits, thus, no linkage between structure and porosity is contrivable. This conclusion cannot be generalized, as the data set is currently too small.

\section{Theoretical Calculations}

To compare the cleaning effects, a mathematical description of the deposit and the cleaning mechanisms is required. Deposits have very different compositions with different materials that show non-regular structures and inhomogeneous porosity. Some build up several layers, while others consist of a main material with embedded parts. To simplify the calculations, the deposit is assumed homogeneous in structure and composition. The deposit consists only of a solid material and porous parts filled with flue gas. To describe the conductivity of such a deposit, it is advisable to use a model structure. Previous researches investigated
Table 4 Analysis of four deposit spots [20]

\begin{tabular}{|c|c|c|c|c|}
\hline & $\begin{array}{l}\text { Type } 1 \\
\text { (Location 1) }\end{array}$ & $\begin{array}{l}\text { Type } 2 \\
\text { (Location 2) }\end{array}$ & $\begin{array}{l}\text { Type } 3 \\
\text { (Location 2) }\end{array}$ & $\begin{array}{l}\text { Type } 4 \\
\text { (Location 3) }\end{array}$ \\
\hline \multicolumn{5}{|l|}{ Sample picture } \\
\hline \multicolumn{5}{|l|}{$\begin{array}{l}\text { Surface } \\
\text { structure } \\
\text { (laser } \\
\text { microscope) }\end{array}$} \\
\hline $\begin{array}{l}\text { Helium density } \\
{\left[\mathrm{g} / \mathrm{cm}^{3}\right]}\end{array}$ & 3.22 & 3.3 & 3.3 & 3.1 \\
\hline Porosity & $56 \%$ & $22 \%$ & $18 \%$ & $30 \%$ \\
\hline $\begin{array}{l}\text { Pore size } \\
\text { distribution }\end{array}$ & $\begin{array}{l}84 \%: \quad 10-100 \\
\mu \mathrm{m} \\
13 \%: 1-10 \mu \mathrm{m}\end{array}$ & $\begin{array}{l}57 \%: 10-100 \mu \mathrm{m} \\
26 \%: 1-10 \mu \mathrm{m} \\
11 \%: 0.1-1 \mu \mathrm{m} \\
6 \%: 0.01-0.1 \mu \mathrm{m}\end{array}$ & $\begin{array}{l}70 \%: \quad 10-100 \\
\mu \mathrm{m} \\
23 \%: 1-10 \mu \mathrm{m}\end{array}$ & $\begin{array}{l}\text { 69\%: } 10-100 \mu \mathrm{m} \\
19 \%: 1-10 \mu \mathrm{m} \\
8 \%: 0.1-1 \mu \mathrm{m} \\
4 \%: 0.01-0.1 \mu \mathrm{m}\end{array}$ \\
\hline $\begin{array}{l}\text { Deformation } \\
\text { temperature }\end{array}$ & $1213^{\circ} \mathrm{C}$ & $1260^{\circ} \mathrm{C}$ & $1258^{\circ} \mathrm{C}$ & $1114^{\circ} \mathrm{C}$ \\
\hline $\begin{array}{l}\text { XRF-analysis } \\
{[\%(\mathrm{~m} / \mathrm{m})]}\end{array}$ & $\begin{array}{l}\mathrm{SO}_{3}>40 \\
\mathrm{SiO}_{2}>10\end{array}$ & $\begin{array}{l}\mathrm{CaO}>30 \\
\mathrm{MgO}>15 \\
\mathrm{Fe}_{2} \mathrm{O}_{3}>10 \\
\mathrm{SO}_{3}<25\end{array}$ & $\begin{array}{l}\mathrm{SiO}_{2}<5 \\
\mathrm{Fe}_{2} \mathrm{O}_{3}>10 \\
\mathrm{SO}_{3} \sim 34\end{array}$ & $\begin{array}{l}\mathrm{SO}_{3}>40 \\
\mathrm{CaO}>30\end{array}$ \\
\hline XRD results & $\begin{array}{c}\text { Haematite } \\
10 \% \text { Rutile } \\
5 \% \\
\text { Ouartz } \\
5 \% \\
\begin{array}{c}\text { Anhydrite } \\
80 \%\end{array} \\
\end{array}$ & 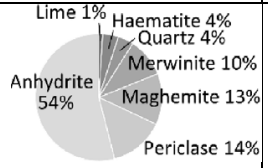 & $\begin{array}{l}\text { Quartz 1\% Perowskite 3\% } \\
\text { Anhydrite Periclase 25\% } \\
57 \%\end{array}$ & $\begin{array}{c}\text { Magnetite } 1 \% \text { Bloedite } 4 \% \\
\text { Quartz } 6 \% \\
\text { Cristobalite } 7 \% \\
\text { Haematite } 8 \% \\
\text { Anhydrite } \\
74 \%\end{array}$ \\
\hline
\end{tabular}


possible heat transfer structure models. These models differ in complexity and integrate different numbers of parameters, e.g. some consider radiation, others not. The heat transfer structure models are interconnections of heat transfer resistors consisting of the raw deposit material and the pores. The most limiting cases are the assumption of a serial connection of deposit and pores and the parallel connection [21]. Russell [22] and Rayleight [23] developed own models that are closer to real structures than the series connection and the parallel connection. To compare heat transfer models and their influence on the stresses inside deposits during a cleaning cycle, all models depicted in Fig. 3 are integrated into the mathematical model. Pore radiation is not considered at the current state.

For the analysis of thermal effects within the deposit, the temperature profile of the whole deposit must be acquainted. As the temperature changes over time, a transient calculation is necessary. A study comparing several transient temperature calculations was conducted prior to the model development, comparing the error function, the Groeber-method, step response and greens function. Under consideration of known parameters, the geometry of the boiler and computational time the error function combined with the semi- infinite wall was selected. Therefore, the temperature calculation for rapid changes is based on the error function. Normally, the error function is valid for walls with even temperature distribution. However, there is a temperature gradient inside the deposit from the surface ( $T_{D ; S F}=$ surface temperature of deposit) to the water tube wall ( $T_{T, o}=$ outer tube temperature). This gradient makes a modification of the error function necessary, which allows an inhomogeneous temperature distribution in the deposit. Equation 1 is the modified error function for an imprinted temperature gradient:

$$
\begin{aligned}
T(\eta)= & T_{W}+\left[\frac{\left(T_{D, S F}-T_{T, O}\right)}{\delta_{D}} \cdot\left(\delta_{D}-x\right)+T_{T, O}-T_{W}\right] \\
& \times \frac{2}{\sqrt{\pi}} \cdot \int_{0}^{\eta} e^{-\eta^{2}} d \eta
\end{aligned}
$$

Equation 1 allows calculating the temperature inside the deposit at any location $x$ at the desired time. Basis is the one- dimensional calculation of a semi- infinite wall. $T_{W}$ is the water temperature at the moment of impact and $\delta_{D}$ is the deposit thickness. As the ratio of pores to solid material affects the deposit properties, additionally, knowledge of the flue gas properties is necessary, assuming that the gas inside the pores is equal to the flue gas. Hence, these properties are calculated from the flue gas composition with aid of the equations in [24], the radiation is considered based on [25]. The model incorporates particle radiation and gas radiation. Carbon dioxide and water are highly relevant as active radiators, whereas nitrogen and oxygen do not send heat radiation. The concentration of other gases is too low. Consequently, carbon dioxide and water are solely part of the gas radiation calculation. Their emissivity spectra are recorded in polynomials, so that the amount of radiation is calculated automatically, based on the input parameters. For a precise calculation, all geometrical data and materials of the boiler are fed

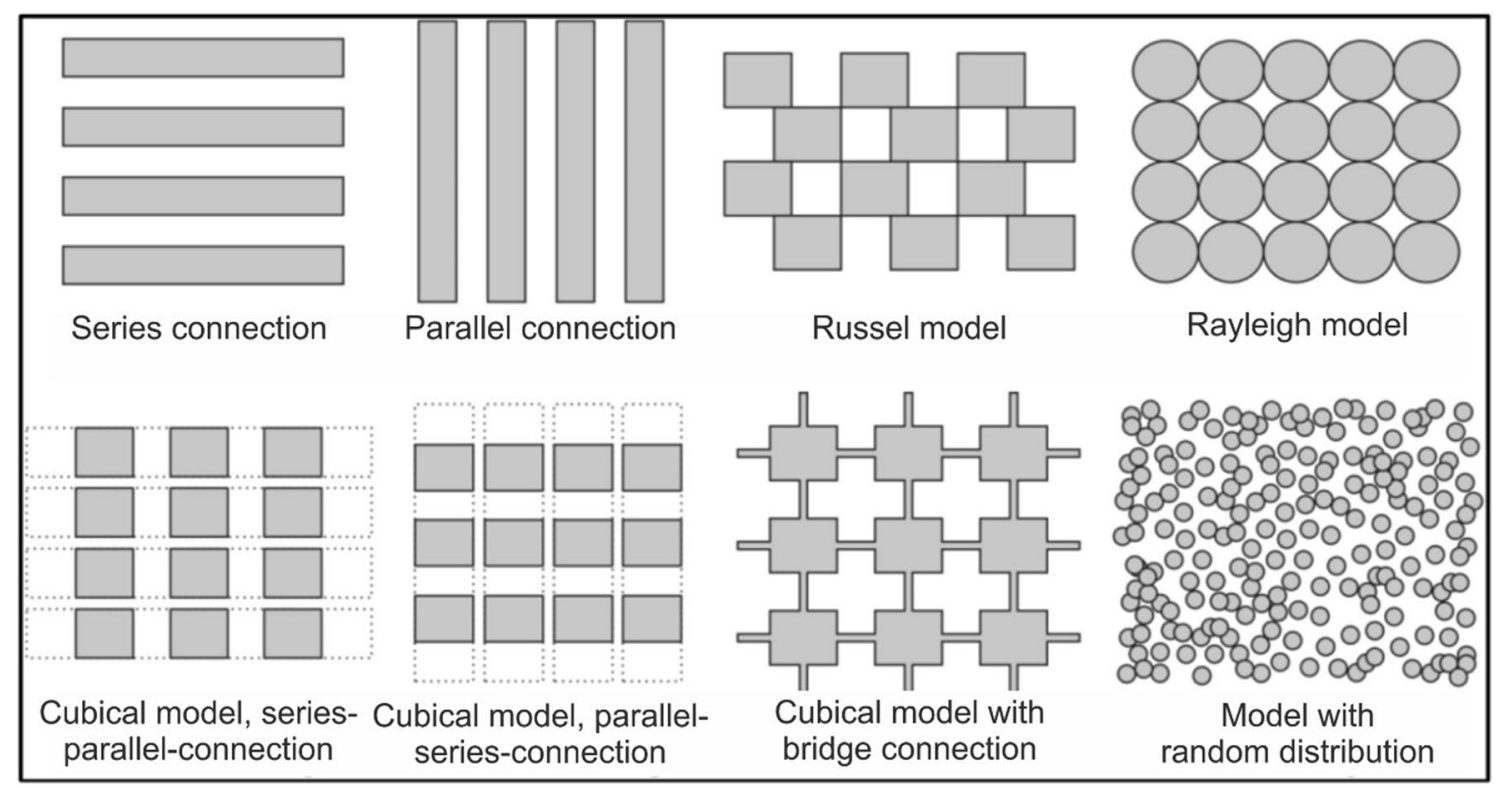

Fig. 3 Heat Transfer Structure Models for the assumption of the effective thermal conductivity [24] 
into the mathematical tool. The properties of the deposits are predetermined based on evaluation of several materials [13]. They can be changed easily to realize parameter studies or to compare the effect of a cleaning cycle with a calibration material.

Not only the deposit, but also the water jet has to be described mathematically - especially, because main target is the optimization of the cleaning setup. Thus, in focus are the influence of the residence time, the amount of water, the water pressure and the momentum of the droplets on the cleaning results. The default setting of the water jet is given for the calculation. Using the continuity equation, the jet velocity is calculated. The pressure of the water jet consists of dynamic pressure and static pressure. The static pressure is the pressure of the inner boiler. The dynamic pressure originates from the water jet velocity. The nozzle size, the outlet pressure and the residence time are fixed values by which the different cleaning effects are influenced. The actual impact pressure is the overall pressure of the water jet converted to the applied surface. The mathematical simulation of the cleaning effects enables an analysis of the importance of each value. Following are different mathematical descriptions of the cleaning effects, which form the basis of the mathematical tool:

The cleaning procedure leads to a cooling of the surface causing thermomechanical stress. The thermomechanical stress $\sigma_{\text {therm }}$ occurs inside the deposit as well as between the deposit and the water wall. This depends particularly on the deposit properties, more precisely on the Young's modulus $E_{M}$, the linear thermal expansion coefficient $\alpha_{c}$ and the Poisson's ratio $v_{c}$. The present calculation considers the global thermomechanical stress through the temperature gradient between the averaged deposit temperature (mean between the surface and the water wall $\vartheta_{D, m}$ ) and the boiling water temperature $\vartheta_{B W}$.

$\sigma_{\text {therm }}=\frac{E_{M} \cdot \alpha_{c}}{\left(1-v_{c}\right)} \cdot\left(\vartheta_{D, m}-\vartheta_{B W}\right)$

Locally, even higher thermomechanical stress is possible. Thermomechanical stress results in tensile stress and compressive stress. The cleaning is successful as soon as one of the stresses exceeds the maximum load of the deposit. The calculation method is elementary knowledge of stresses. Nonetheless, the number of material parameters is anyway already high. Material parameters, which cannot be measured during operation of the boiler, must be estimated. Hence, the number of material parameters should be kept as low as possible. For that reason, the equations are kept that simple.

A detailed mathematical simulation of the momentum requires knowledge of the droplet spectrum. This is not known for every type of nozzle. Therefore, the overall impact area of the jet ( $d_{i m p}=$ impact diameter) can be used for the calculation and has to be estimated, if unknown. Here, general jet enlargement equations can be considered. Besides, the orifice of the nozzle ( $d_{\text {out }}=$ outlet diameter of nozzle) and the outlet pressure of the water jet have to be available. As described above, they serve for the calculation of the jet velocity $v_{\text {out }}$, which in turn is necessary for the calculation of the dynamic pressure. Additionally, there is need of the density of the water $\rho_{W}$. Besides, the static pressure $p_{s}$ in the combustion chamber is necessary for the calculation of the momentum, which results in compressive stress in the impact area $\sigma_{m o m, 1}$ and shear stress at the edge $\sigma_{m o m, 2}$. These values normally can be supplied by the control center.

$\sigma_{\text {mom }, 1}=\frac{\rho_{W}}{2} \cdot\left(v_{\text {out }} \cdot \frac{d_{\text {out }}}{d_{\text {imp }}}\right)^{2}+p_{s}$

$\sigma_{m o m, 2}=\frac{\sigma_{m o m, 1} \cdot d_{i m p}}{\delta_{D} \cdot 4}$

The pore evaporation assumes, that the water is penetrating into open pores, where the water evaporates. Through the following cleaning water the pores are sealed, which leads to a pressure increase during the evaporation of the water. This may result in the deposit splitting off from the inside. Likewise, further possible cleaning effects described in literature besides spalling owed to penetration of water into pores, e.g. dissolution of salt are not further investigated within this paper. In focus are the surface effects.

\section{Results and Discussion}

\section{Parameter Study}

Main target of the study is the improvement of the cleaning. Therefore, a parameter study is conducted, that shall compare deposit properties and their influence on the cleaning ability of the deposit. The equations presented in the previous chapter leading to a complete heat transfer model allow such a parameter study to determine the influence of the deposit constitution. This comprises not only properties, but also layer thickness, porosity or structure. The results of the parameter variation are presented in the following. Firstly, the effects of the parameters are described. Afterwards, the results are summarized and depicted. To ensure comparability, the parameter study is realized with a precise parameter set as summarized in Table 5 .

The values given correspond to typical experience for the combustion in several waste incinerators. Variation of these parameters only arises if the specific parameter is 
Table 5 Parameter selection for mathematical calculations
Flue gas temperature: $780{ }^{\circ} \mathrm{C}$

Cleaning cycle: $17 \mathrm{~s}$

Structure model: Russell model

Conductivity of deposit: $0.85 \mathrm{~W} /(\mathrm{m} \mathrm{K})$

Specific heat capacity of deposit: $1800 \mathrm{~J} /(\mathrm{kg} \mathrm{K})$

Steam generator working fluid pressure: $40 \mathrm{bar}$
Water flow rate: $0.0008 \mathrm{~m}^{3} / \mathrm{s}$

Deposit layer thickness: $0.005 \mathrm{~m}$

Porosity of deposit: $40 \%$

Density of deposit: $3800 \mathrm{~kg} / \mathrm{m}^{3}$

Pore shape: cylindrical undergoing the parameter study. The calculation was also deployed for coal-fired power plants.

\section{Structure Analysis}

The structure of the deposit affects the heat transfer through the deposit. Hence, possible structures are implemented in different heat transfer models as presented in the chapter "materials and methods" of this paper. The deposit can consist of several layers (series connection), be shaped like small spheres that are surrounded by flue gas (model of random distribution) or be perforated with cylindrical pores from the surface to the water wall (parallel connection). The serial connection is a typical model in the super heater section, where several layers form the deposits. Such a deposit type was described in the literature study in the introduction section by Hansen [11]. The model of random distribution is especially expectable in plants with hot flue gas or fly ash with a low melting temperature (high alkali content), where the fly ash was molten, formed spheres and then got stuck in spheres on the walls. The parallel connection is a homogeneous deposit with pores or embedded parts, like in sintered deposits. The knowledge of the deposit structure is not always present, but the heat transfer has a direct effect on the thermomechanical stress during the cleaning procedure. In case of inexperience, the heat transfer has to be estimated in range of the heat transfer structure models. Therefore, the heat transfer models were compared in a parameter study. The parallel connection and the series connection are the limiting cases, whereas all other models have to fit in between. The parallel connection supports the rise of thermomechanical stress directly at the water walls while series connection causes thermomechanical stresses inside the deposit. Especially deposits with a high thermal conductivity and parallel connection may be dangerous for the water tube walls. The temperature is evenly distributed in the deposit and leads to a cooling of the water tube wall. Figure 4 shows the temperature inside the deposit. Compared are all the models that were already visualized in Fig. 3.

In Fig. 4, the temperature curve over the deposit thickness is visible after a cooling of the surface for $1 \mathrm{~s}$. The $x$-position of $0 \mathrm{~mm}$ represents the deposit surface inside the incinerator, the maximum value of $x$ is the contact position of the deposit and the water wall. In steady state, the temperature

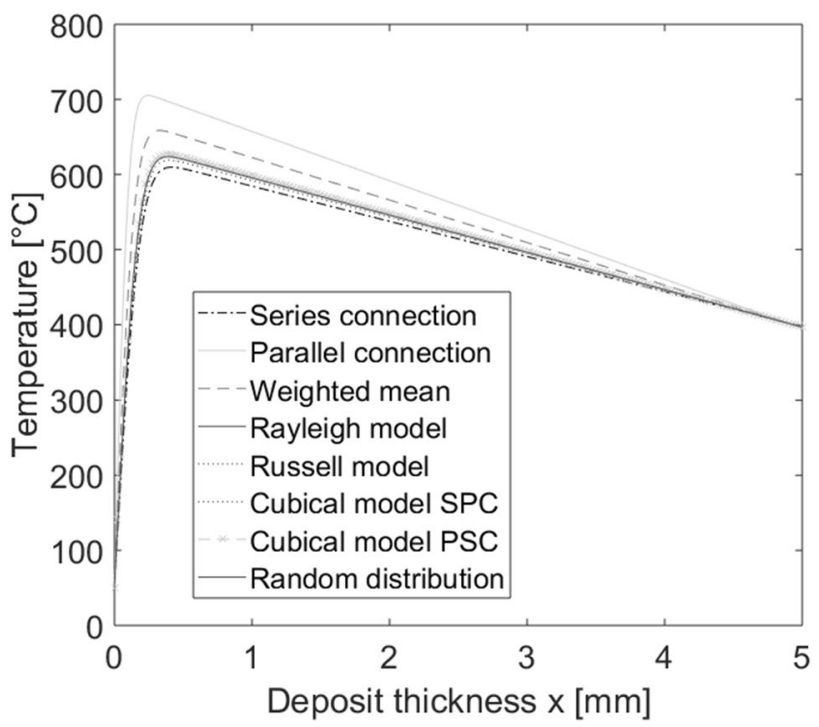

Fig. 4 Temperature course inside a deposit during the cooling process assuming different deposit structures

distribution can be approximated by a linear curve. Through the surface cooling, the temperature has a maximum inside the deposit. Series Connection shifts the maximum into the center, parallel connection to the surface. This knowledge is important for the estimation, where the thermomechanical stress may arise. The reason, as mentioned above, is a better thermal conductivity of the deposit with a homogeneous composition compared to layered deposits.

\section{Porosity Analysis}

The porosity affects the heat transfer. Depending on the heat transfer model, the effect of the porosity differs. The parameter study focused on the porosity effect on the assumption of the Russell model. For rising porosity, the results show a growth of the peak temperature inside the deposit assuming all other deposit properties to be constant. Figure 5 shows the temperature distribution starting with a porosity of $0 \%$ up to a porosity of $80 \%$. The structure of the figure is equal to the structure of Fig. 4. The left side is the deposit surface $(x=0 \mathrm{~mm})$, the right side the water tube wall's surface. The cooling started $1 \mathrm{~s}$ ago. 


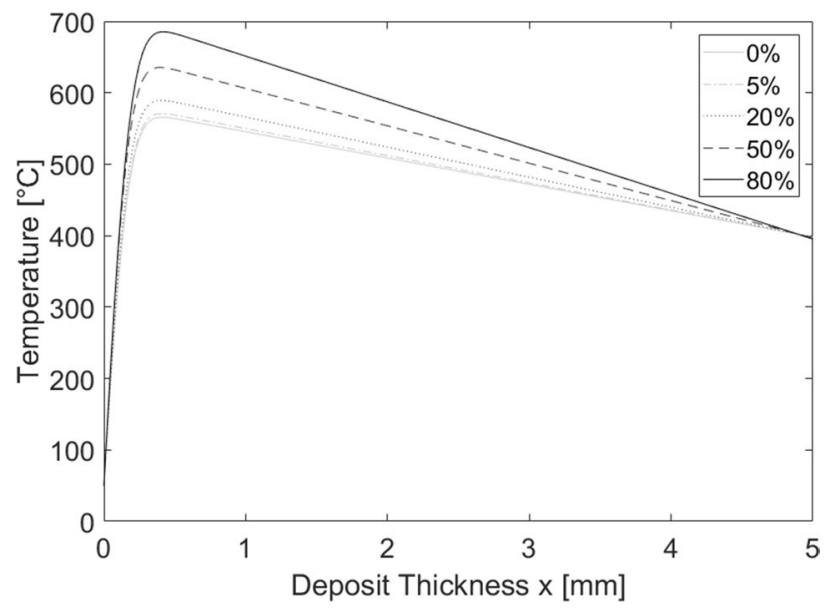

Fig. 5 Temperature course during a cleaning cycle for different porosities

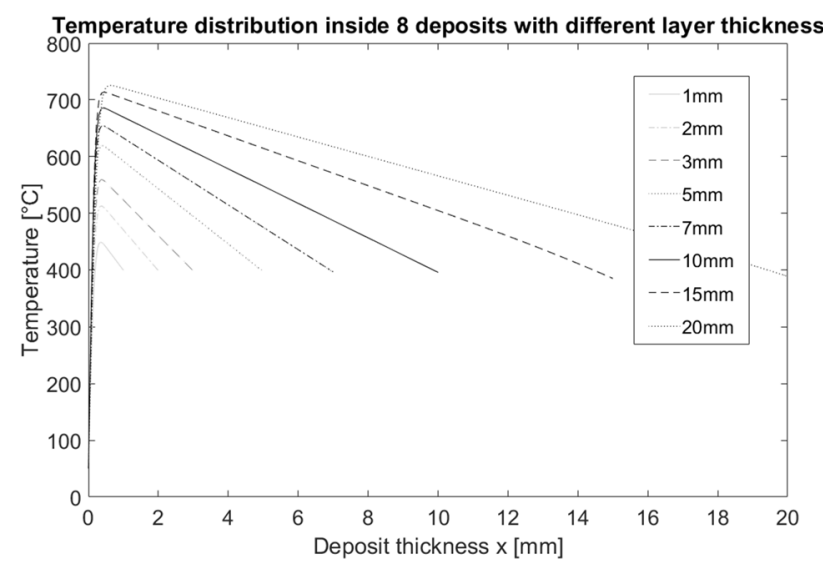

Fig. 6 Temperature course inside deposit dependent on deposit thickness

On one hand, a higher porosity causes higher thermomechanical stress, because the effective thermal conductivity decreases, while on the other hand, porous deposits may have a higher elasticity and, thus, may withstand higher stresses [5]. To evaluate the influence, the results have to be compared with the material strength.

\section{Layer Thickness Analysis}

The deposits grow inside the boiler until they reach an equilibrium by natural shedding, they plug the flue gas path or they are removed by cleaning systems. The operator faces the question of the ideal cleaning time. Normally, orientation for that is a too strong limitation of the heat output. Withal, the question arises whether the layer thickness affects the efficiency of the cleaning. Thicker layers show higher deposit temperatures assuming same deposit properties and on that account support the cleaning through thermomechanical stress. In Fig. 6 is a comparison of eight deposits with different thickness. The thinnest deposit has a thickness of $1 \mathrm{~mm}$, while the thickest deposit reaches $20 \mathrm{~mm}$. All eight deposits have their surface at $0 \mathrm{~mm}$. The temperature graphs presented in Fig. 6 show higher temperatures of thicker deposits. Again, the structure of the figure is equal to Figs. 4 and 5, showing on the left side the deposit surface that is cooled through the cleaning water and on the right side the water tube wall's surface.

Problematically, the deposit growth goes hand in hand with a change of the deposit structure, which cannot be detected by the present mathematical investigation. Studies made in [5] showed that thicker layers can often bear higher stresses due to their structure. Thus, a general recommendation based on the layer thickness of the deposit is impossible. Figure 7 shows the development of thermomechanical stress and shear stress for rising deposit thickness on the assumption of similar deposit properties. The shear stress considers a material increase in the shear level (the area between the impinged and the non-impinged material) for thicker deposit layers and, therefore, a shear stress decrease. However, the thermomechanical stress rises through the increasing temperature gradient.

Crucial is, that an adjustment of cleaning parameters does not improve all cleaning effects equally, but, as shown above, may rather have opposite effects. Consequently, the cleaning setup has to be adjusted in such a manner that the most efficient cleaning effect is improved. In the example presented above the thermomechanical stress is much higher than the shear stress. Therefore, the increase of thermomechanical stresses would have a higher effect on the cleaning result than the increase of shear stress. The adjustment should be made under consideration of that knowledge.

\section{Deposit Properties Analysis}

In detail deposit properties mean density, specific heat capacity and heat conductivity. Since these properties are closely related to each other they cannot be examined independently for actual deposits. Moreover, they apply to the solid material with their values changing dependently on the deposit's porosity. The present study considered pure solids. Additionally, the compared materials are pure substances with known material properties. They serve as a plausibility check and do not represent real deposits. The connection of the three influencing values can be summarized in the thermal diffusivity $a$ :

$a=\frac{\lambda}{\rho \cdot c}$

To evaluate the deposit properties for realistic combinations, seven materials with different property combinations 
Fig. 7 Comparison of thermomechanical stress and shear stress for defined cleaning setup and different deposit thickness

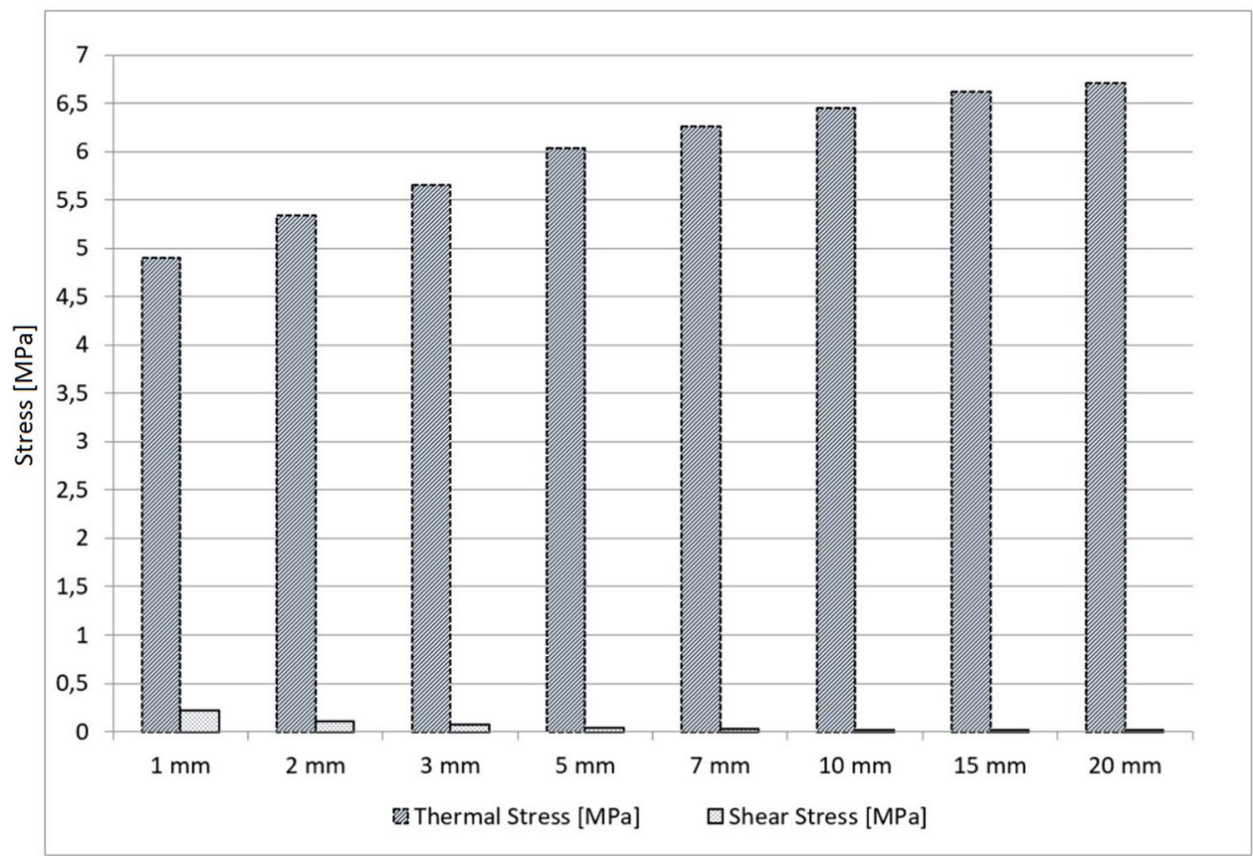

were chosen. The deposit properties were obtained from literature [26-31]. The materials were ceramics, concrete, glass, gypsum, marble, sandstone and steel. The materials were selected in such a way, that the diffusivity depicts a wide range of possible materials starting from
$7.31 \mathrm{E}-08 \mathrm{~m}^{2} / \mathrm{s}$ (for gypsum) up to $1.24 \mathrm{E}-05 \mathrm{~m}^{2} / \mathrm{s}$ (for steel). Nonetheless, they are only an assumption for real deposit material properties.
Fig. 8 Comparison of material strength with thermomechanical stress during cleaning procedure

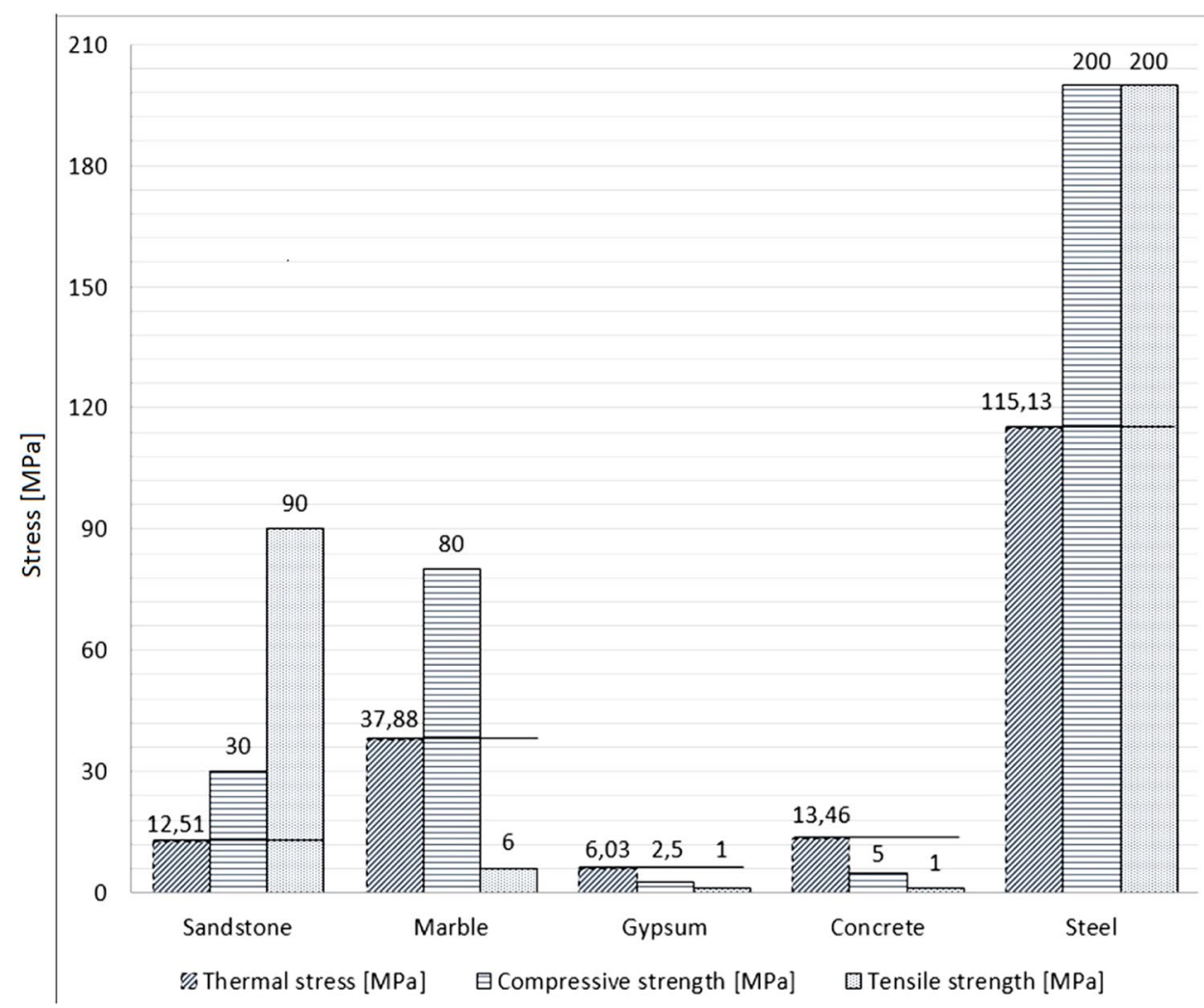


Figure 8 visualizes the comparison of thermomechanical stresses with compressive strength and tensile strength for the selected materials. The thermomechanical stress was calculated inside the deposits assuming a deposit thickness of $5 \mathrm{~mm}$, a water volume flow rate of $0.8 \mathrm{l} / \mathrm{s}$ and the use of the Russell model. Flue gas temperature and other necessary values were calculated from the incinerator values. Obviously, some materials face comparably low thermomechanical stress, but nevertheless cannot stand it (Gypsum and concrete), while others can withstand much larger values (marble, Steel).

Essential gain of knowledge is that the deposit properties are a key point for the cleaning adjustment. In case of the present materials, gypsum, marble and concrete could be removed easily through thermomechanical stress. At the same time, the chosen cleaning adjustment could not remove the sandstone, but a slight increase of the thermomechanical stress inside the deposit could lead to a successful cleaning. An adjustment of the cleaning for steel is impossible. Therefore, the use of water for the removal would never be successful and could be saved. Figure 9 visualizes the temperature distribution inside the deposit during the cleaning with the same parameter set and figure structure as in the aforementioned chapters.

The graphs show that the peak position is depending on all the presented aspects: the porosity, the heat transfer structure model, the deposit thickness and the deposit properties. Materials with a large thermal conductivity (e.g. steel) develop no clear peak, thus, they are very unsusceptible to thermomechanical stress. Here, other removal mechanisms must be found, e.g. a high momentum.

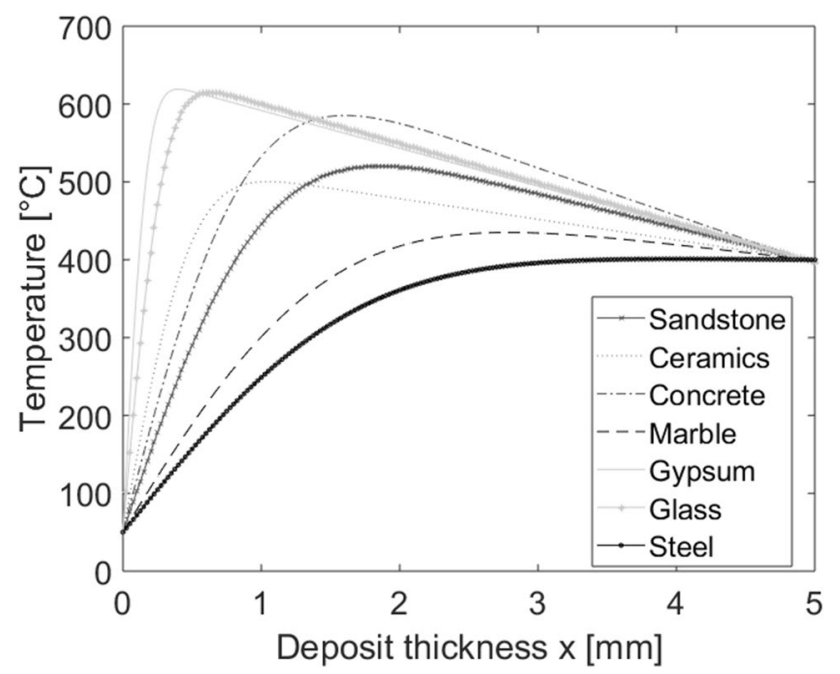

Fig. 9 Comparison of temperature courses for different materials

\section{Application of the Model to Real Cleaning Procedures}

For proceeding from pure substances to real deposits a data collection is necessary. Therefore, the deposit sensor is deployed, which was expounded further upwards. The sensor delivers deposit data during the operation of the incinerator. The sensor was installed at the second path of the waste incinerator in Coburg, Germany. At that location Coburg holds a shower cleaning system. The cleaning time is chosen manually by the operator. The sensor delivers deposit data during the operation of the incinerator in Coburg at the second path. Its setup is depicted in Fig. 10.

The deposit sensor was used to collect the thermal diffusivity of a deposition before and after the cleaning and its porosity. The sensor estimates the thermal diffusivity in a certain range. The range is set by the heat transfer structure models that were illustrated in chapter 3 of the present article. Knowing the deposit's thickness makes the whole system much more precise, because it is possible to determine an exact thermal conductivity and not only to estimate it. Thus, a laser distance sensor was installed additionally, that delivered the deposit's thickness. The system was already mentioned in the current state of the art. Likewise, the sensor measured before and after the cleaning. An online monitoring system, called online balancing tool, transmitted operational data such as volume flow rate, dust rate and flue gas temperature. Furthermore, the monitoring system gave an inside into the success of the cleaning procedure. This was possible through the evaluation of the temperature range over the boiler. The collected data were fed into the simulation program and could be compared regarding transferability. Table 6 contains the measured data of three cleaning cycles. The monitoring program delivered the flue gas temperature. The cleaning protocol contained the volume flow rate of the cleaning water as well as the residence

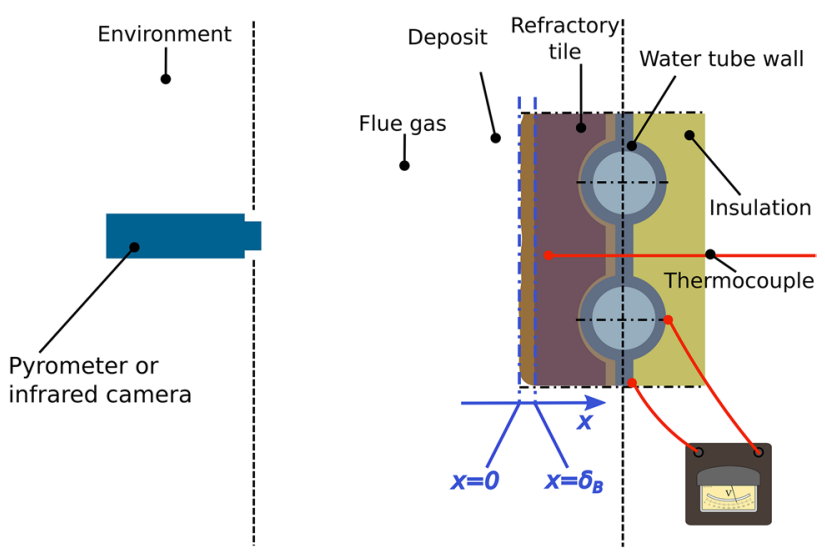

Fig. 10 Setup of the deposit sensor [16] 
Table 6 Measured data of the incinerator in Coburg

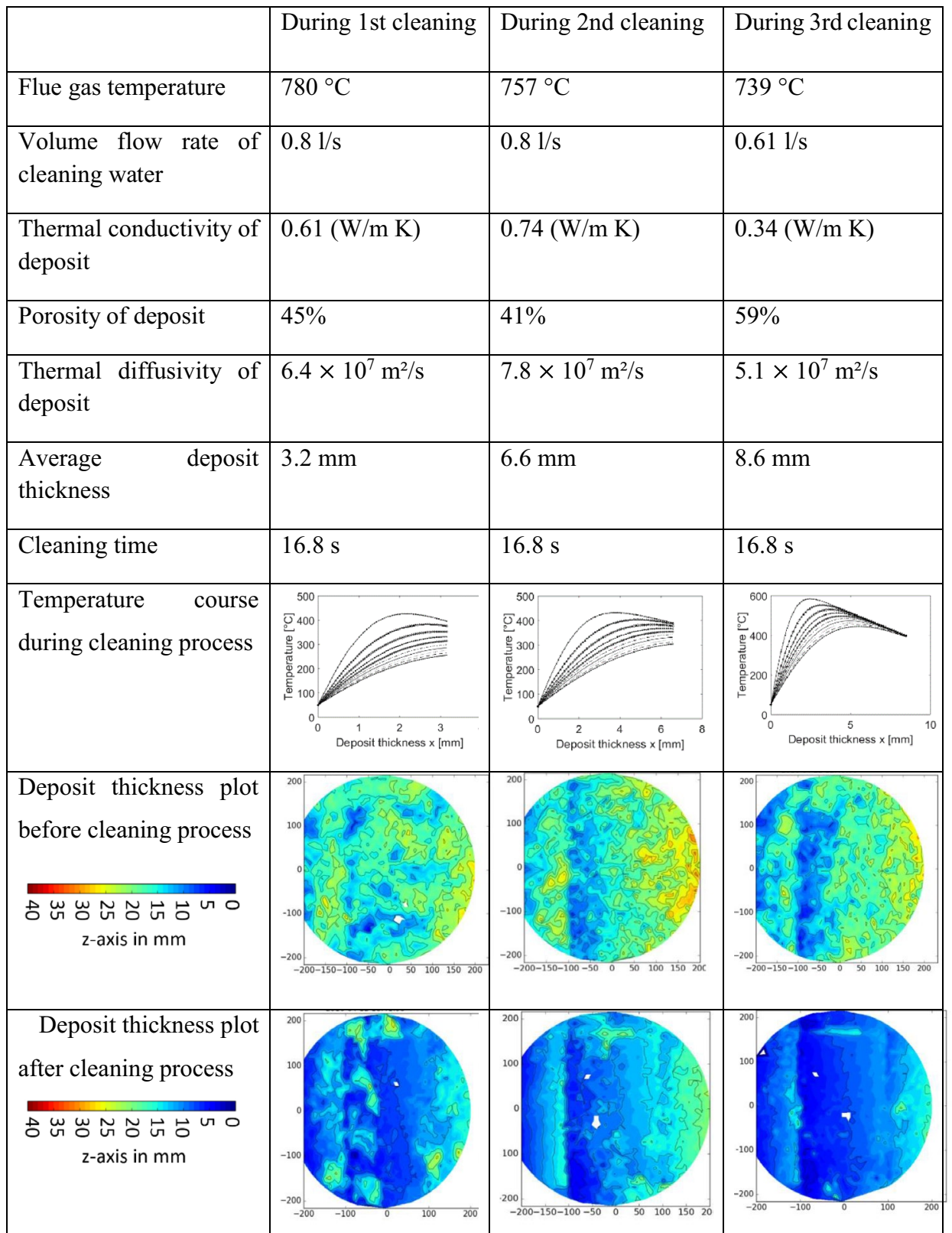

time. The thermal conductivity of the deposit and the porosity were measured with aid of the deposit sensor. The laser distance sensor delivered the deposit thickness. Additionally, the laser distance sensor is able to record deposit thickness plots, which do not only show the mean deposit thickness, but a spatial- dependent map of the deposit thickness. These maps enable a visual evaluation of the cleaning success. At last, the table contains temperature courses inside the deposits. Here, the different graphs are not compared like in the parameter studies. They show the temporal progress of the cooling. The lowest curve presents the temperature profile of the deposit at the end of the cleaning cycle, here $16.8 \mathrm{~s}$ for all three cleaning cycles.
The temperature curves are taken to evaluate the cleaning regarding thermomechanical stresses, while the deposit thickness maps help evaluating the success of the three cleaning cycles. The left side of the temperature curves again shows the surface of the deposit, where the water impinges upon the deposit, the right side is the water tube wall. The highest curve in each diagram shows the temperature shortly after the start of the cleaning process (approximately $1 \mathrm{~s}$ ), the lowest curve, as mentioned above, is the time, when the cleaning stopped, here $16.8 \mathrm{~s}$. All other time steps are distributed evenly in between. The progress of the curves is as expected, because the third deposit has a much lower conductivity, caused through the high porosity. This is why the temperature gradients are much larger and the temperature changes are much lower. 
The deposit removal was successful for all three cleaning procedures. The thickness plots at all locations before the cleaning process show an even deposit distribution, the plots subsequent to the cleaning contain less deposits, especially after the second and third cleaning cycle. Nonetheless, the results of the analysis have several differences. Without knowledge of the Young's modulus and the thermal expansion coefficient, the determination of the actual arising thermomechanical stress is impossible. Thus, a derivation from the theoretical calculation is not possible. However, a comparison of the three deposits is possible and shows that the 3 rd cleaning procedure was most suitable to the deposit situation. During the first and second cleaning, the use of water was too excessive. This is obvious because the entire deposit cooled down so that the thermomechanical stress was transmitted to the water tube wall risking damage of the latter. A shorter residence time or a lower water flow rate would have led to a similar cleaning result without cooling down the whole deposit up to the water tube wall.

Due to the layer thickness and different deposit properties, the amount of water and the cleaning setup used for the 3 rd cleaning were much more suitable. The cooling reached to the middle of the deposit and high thermomechanical stresses combined with the compressive stress of the water onto the deposit led to a deposit removal and did most probably not endanger the water tube wall. The wall remained at its normal operation temperature, which increases the lifetime of the tubes. Confiningly, temperature curves do not contain the deposit removal during the cleaning cycle. From this perspective, a lowering of the water flow rate or the residence time is even more reasonable, because thinner deposits induce further cooling of the water tube wall.

\section{Conclusion and Outlook}

The removal of deposits through water cleaning systems is subject to fundamental physical effects on the deposit surface or inside the deposit pores. There is a type of deposit that only faces surface effects. Others might allow a penetration of water, but nonetheless, the surface effects are still valid. Existing deposit samples were investigated and classified to spot properties that especially have an influence on the cleaning effect of water cleaning systems. This was realized both with deposits collected online, using an in-situ measurement system, and samples collected during shut downs. Here, the porosity appeared as one of the main differences between the different deposit types. Therefore, the porosity was in focus for the follow-up investigation and other properties should be linked to porosity. Afterwards, based on the obtained results, the current paper investigated surface effects mathematically, namely the thermomechanical stress and the momentum of the water, and exposed their influencing variables. Part of the study was the description of the transient temperature changes inside deposits due to cleaning effects. This was realized with the error function and the semi- infinite wall model. The function had to be adjusted to the temperature profile during steady state, as deposits do not have a homogeneous temperature. Subsequently, parameter studies followed, analyzing the influence of the deposit properties summarized as thermal diffusivity, the deposit's porosity, layer thickness and structure on the cleaning result. The analysis indicated that the physical effects show very different results and knowledge of the properties may lead to an improved cleaning. Hence, the presented mathematical model and the displayed sensor systems can be combined, giving operators the possibility to diagnose the deposit and apply the knowledge for an improved cleaning.

In the future, collection of deposits will be extended and the systematic deposit analysis pursued. Aim is the acquisition of as many different deposit types as possible, always with focus on their properties and their cleaning ability. The used measurement setup will also be expanded to measure more properties directly at the boiler location, e.g. the surface profile, the composition or the surface temperature. The reconstruction of the apparatus is already in progress.

The presented mathematical model was applied to the waste incinerator in Coburg. Under use of several sensor systems, namely the deposit sensor, the laser distance sensor and a monitoring system, the deposits could be analyzed during operation of the waste incinerator. Firstly, the sensors could be used to measure the deposit's thickness, porosity, thermal diffusivity and thermal conductivity. Then, the sensors were used to evaluate three cleaning cycles. Here, the process control was incorporated to consider flue gas properties and the cleaning setups. Plots of the deposit thickness before and after the cleaning cycles showed, that all three cleanings could remove the deposits. The mathematical model analyzed the cleaning procedures regarding their effect on the water tube wall, especially regarding thermomechanical stress. Through the model, the amount of cleaning water could be reduced from 0.8 to $0.6 \mathrm{l} / \mathrm{s}$, using the same cleaning time, while the deposits were equally removed. Additionally, the reduction of cleaning water resulted in less thermomechanical stress in the water tube wall, because the wall remained at higher temperature. Additionally, erosion effects through droplets are less probable with the adjusted cleaning. Hence, the model showed, how an adjusted cleaning cannot only improve the success of the cleaning result, but also may help to extend the lifetime of components. Concomitant the model and the precedent investigation are a stride to fully understand what happens within the deposit during the cleaning process. 
Acknowledgements Open Access funding provided by Projekt DEAL. The authors acknowledge the financial support received from Clyde Bergemann Gmbh for establishing the mathematical model. Besides the authors acknowledge the support of RWE with providing deposit material, the "Zweckverband für Abfallwirtschaft Nordwest-Oberfranken" for the valuable help and data provided and Dr. Kathrin Gebauer (TU Dresden) for the laboratory analysis.

\section{Compliance with Ethical Standards}

Conflict of interest The authors report no conflicts of interest. The authors alone are responsible for the content and writing of this article.

Open Access This article is licensed under a Creative Commons Attribution 4.0 International License, which permits use, sharing, adaptation, distribution and reproduction in any medium or format, as long as you give appropriate credit to the original author(s) and the source, provide a link to the Creative Commons licence, and indicate if changes were made. The images or other third party material in this article are included in the article's Creative Commons licence, unless indicated otherwise in a credit line to the material. If material is not included in the article's Creative Commons licence and your intended use is not permitted by statutory regulation or exceeds the permitted use, you will need to obtain permission directly from the copyright holder. To view a copy of this licence, visit http://creativecommons.org/licenses/by/4.0/.

\section{References}

1. Obernberger, I., Biedermann, F., Widmann, W., Riedl, R.: Concentrations of inorganic elements in biomass fuels and recovery in the different ash fractions. Biomass Bioenergy 12(3), 211-224 (1997)

2. Schroer, C., Konys, J.: Rauchgasseitige Hochtemperatur-Korrosion in Müllverbrennungsanlagen. Ergebnisse und Bewertung einer Literaturrecherche [Fuel gas sided high temperature corrosion in waste incinerators-results and evaluation of a literature research], p. 6695. Forschungszentrum Karlsruhe, Karlsruhe, Technik und Umwelt Wissenschaftliche Berichte FZKA, Karlsruhe (2002)

3. Krause, H.H., Vaughan, D.A., Miller, P.D.: Corrosion and deposits from combustion of solid waste. J. Eng. Power 95(1), 45 (1973)

4. Bryers, R.W.: Fireside slagging, fouling, and high-temperature corrosion of heat-transfer surface due to impurities in steamraising fuels. Prog. Energy Combust. Sci. 22(1), 29-120 (1996)

5. Graube, F., Grahl, S., Rostkowski, S., Beckmann, M.: Optimisation of water-cannon cleaning for deposit removal on water walls inside waste incinerators. Waste Manag. Res. 34(2), 139-147 (2016)

6. Breeding, C., Ziegler, T.W.: Performance of water cannons at Labadie," in Proceedings of the IJPGC 2002, International Joint Power Generation Conference Power: Presented at the 2002 International Joint Power Generation Conference, June 24-26, 2002, pp. 791-795, Scottsdale, Arizona, USA, (2002)

7. Rostkowski, S., Beckmann, M., Rinderle, C.: Wege zu einer optimierten Nassreinigung von Strahlungsheizflächen [Proceedings to an optimized water cleaning of radiation surfaces]. In: ThoméKozmiensky, K.J., Beckmann, M. (eds.) Energie aus Abfall. Verlag Karl Thomé-Kozmiensky, Neuruppin (2013)

8. Mueller, C., Frach, M., Tirkschleit, M., Tandra, D., Breeding, C.: Fuel-specific on-load boiler cleaning solutions in waste incineration plants: challenges, concepts, experiences," in Proceedings of the 18th Annual North American Waste to Energy Conference 2010, NAWTECH 2010: Advancing waste to energy through research and technology, waste to energy contracts and development initiatives, waste to energy: sustainable green power and waste management, improving waste to energy plant operations; presented ... May 11-23, 2010, pp. 277-282, Orlando, Florida, USA, 2010, (2010)

9. Harpeng, J., Warnecke, R.: Beurteilung der Online-Belagsabreinigung durch Rußbläser und Klopfer [Assessment of online cleaning through soot blower and knocker]. In: Beläge und Korrosion in Großfeuerungsanlagen, VDI-Seminar 430505, 14.06.-15.06.2005

10. Gumz, W., Kirsch, H., Mackowsky, M.-T.: Schlackenkunde. Springer-Verlag, Berlin (1958)

11. Hansen, L.A., et al.: Influence of deposit formation on corrosion at a straw-fired boiler. Fuel Process. Technol. 64(1-3), 189-209 (2000)

12. Żelkowski, J.: Kohlecharakterisierung und Kohleverbrennung [coal characterization and coal combustion]: Kohle als Brennstoff, Physik und Theorie der Kohleverbrennung. Technik, VGB PowerTech Service (2004)

13. Grahl, S.: Charakterisierung von Ablagerungen an Membranwänden von Dampferzeugern [Characterization of depositions on membrane walls of steam generators]. Dissertation, Institut für Energietechnik, TU, Dresden.

14. Koschack, R., Hoven, G.: Method and apparatus for monitoring the formation of deposits in furnaces. US7607825 B2, USA.

15. Bohnes, S., Wirtz, S., Scherer, V.: Einfluss von Belägen in Hochtemperaturprozessen: Simultane Messung der Wärmeleitfähigkeit und der spektralen Emissionskoeffizienten in Abhängigkeit der stofflichen Eigenschaften [Influence of deposits in high temperature processes]. AiF IGF-Forschungsvorhaben 14200/N. (2008)

16. Reiche, M., Grahl, S., Beckmann, M.: Advanced monitoring of the fouling process on water walls. Fuel 216, 436-444 (2018)

17. F. Graube-Kühne, S. Grahl, and M. Beckmann.: Messapparatur zur in-situ-Vermessung von Ablagerungen [Measurement Setup for the in-situ analysis of deposits]. In: 29. Deutscher Flammentag, Ruhr-Universität Bochum: Bochum, 2019.

18. Gottfried, B.S., Lee, C.J., Bell, K.J.: The leidenfrost phenomenon: film boiling of liquid droplets on a flat plate. Int. J. Heat Mass Transf. 9(11), 1167-1188 (1966)

19. Leidenfrost, J.G.: De Aquae Communis Nonnullis Qualitatibus Tractatus [A tract about some qualities of common water]. Publisher Ovenius, Duisburg (1756)

20. Graube-Kühne, F., Bernhardt, D., Grahl, S., Beckmann, M.: In-situ-Ablagerungsversuche für eine optimierte Belagsreinigung in Dampferzeugern [In-situ-Deposit-Experiments for an optimized Deposit Removal in Steam Generators]. In: Pohl, M. (ed.) Dampferzeugerkorrosion 2019. SAXONIA, Freiberg (2019)

21. VDI-Wärmeatlas.: Springer, Berlin. (2006)

22. Russel, H.: Principles of heat flow in porous insulators. J. Am. Ceram. Soc. 18(1), 1-5 (1935)

23. Rayleigh, L.V.I.: On the influence of obstacles arranged in rectangular order upon the properties of a medium. Lond. Edinb. Dublin Philos. Mag. J. Sci. 34(211), 481-502 (1892)

24. Gupta, R.P., Wall, T.F., Baxter, L.: The thermal conductivity of ash deposits. In: Gupta, R.P., Wall, T.F., Baxter, L. (eds.) Impact of Mineral Impurities in Solid Fuel Combustion, pp. 65-84. Kluwer Academic Publishers, Boston, MA (2002)

25. Brandt, F.: Wärmeübertragung in Dampferzeugern und Wärmeaustauschern, 2nd edn. Vulkan-Verl, Essen (1995)

26. Kreith, F.: Heat and Mass Transfer-Mechanical Engineering Handbook. CRC Press, Boca Raton (1999)

27. Alfes, C., Schießel, P.: Physikalisch-mechanische Eigenschaften von Sandsteinen [physical and mechanical properties of sand stone]. Fraunhofer IRB, Stuttgart (1992)

28. Huster, U.: Tragverhalten von einschaligem Natursteinmauerwerk unter zentrischer Druckbeanspruchung: Entwicklung und Anwendung eines Finite-Elemente-Programmes. Zugl.: Kassel, Univ., Diss, 2000. Kassel University Press, Kassel (2000) 
29. Fischer, K.: Altbau und Denkmalpflege Informationen [old building and monument preservation information]. https://www.konra d-fischer-info.de/29bau13.htm. Accessed 1 Aug 2019

30. Bluhm, H.: Baustofftabellen und Wärmeleitzahlen [Table of construction materials and Conductivity data]. https://www.bau-dochselber.de/energie/waermeleiter.html. Accessed 1 Aug 2019.
31. G. Kortuem and H. Lachmann, Einführung in die chemische Thermodynamik: Phänomenologische u. statistische Behandlung, 7th ed. Verl. Chemie; Göttingen Vandenhoeck \& Ruprecht, Weinheim, 1981.

Publisher's Note Springer Nature remains neutral with regard to jurisdictional claims in published maps and institutional affiliations.

\section{Affiliations}

\section{Franziska Graube-Kühne ${ }^{1,3}$ (1) Nina Heißen ${ }^{2} \cdot$ Sebastian Grahl ${ }^{1} \cdot$ Michael Beckmann $^{1} \cdot$ Bhaumik Patel $^{2}$}

$\triangle$ Franziska Graube-Kühne

franziska.graube-kuehne@tu-dresden.de

1 Chair of Energy Process Engineering, Institute of Process Engineering and Environmental Technology, Dresden

University of Technology, George-Bähr-Straße 3b, 01069 Dresden, Germany
2 Clyde Bergemann GmbH, Schillwiese 20, 46485 Wesel, Germany

3 TU Dresden, Walther-Pauer-Bau Room 301, George-Bähr-Str. 3b, 01069 Dresden, Germany 